\title{
Instagram sebagai Media Peluntur Literasi dan Kosa Kata Bahasa Indonesia pada Era Revolusi Industri 4.0 di Kalangan Generasi Millenial
}

\author{
Anggi Prastiwi Kumalasari \\ Program Studi Pendidikan Biologi, FKIP, Universitas Sebelas Maret Surakarta, 57126 \\ Email : apkumalasari@gmail.com
}

\begin{abstract}
The development of various sciences and technologies in the era of the industrial revolution 4.0 in Millennial generation brought many impacts on the development of Indonesian. One of these impacts is a decline in the vocabulary and writing skills of Indonesian that is correct according to PUEBI's rules on Instagram sosial media especially on accounts @young_lex18. This causes the fading of the function of Indonesian as an authoritative state language. The purpose of this study was to describe the misuse of Indonesian vocabulary and analyze the types of language errors that often appear on Instagram sosial media. In this study, the method used is a qualitative descriptive method. This method is done by taking several upload samples from an Instagram account by capturing the screen. The upload sample is not changed, not treated, and not manipulated. The treatment given is only by comparing and analyzing vocabulary errors and writing sentences in one upload with other uploads on one Instagram account. The results obtained in this study were found that many uploads did not comply with the PUEBI rules with various errors such as punctuation, word selection, the existence of abbreviations, and others. The impact of the research on this phenomenon is that the type of language writing errors found on Instagram sosial media can be detected so that it can be used as a lesson in subsequent writing so that the same mistakes are not repeated. This is done so that the preservation of Indonesian language can be maintained and applied in daily life, especially on sosial media sosial media Instagram
\end{abstract}

Keywords: Instagram, vocabulary, language writing, PUEBI rules

\section{Pendahuluan}

Tingkat penggunaan Instagram di Indonesia pada era revolusi industri 4.0 di kalangan generasi Millenial mengalami perkembangan secara pesat. Seiring perkembangan dan kemajuan teknologi ini, banyak terjadi kesalahan dalam penggunaan bahasa Indonesia baik secara lisan maupun tulisan di media sosial, khususnya Instagram. Hal ini menyebabkan semakin lunturnya penggunaan kaidah bahasa Indonesia yang benar. Hal ini ditunjukkan dengan tidak diterapkannya kaidah PUEBI dalam penullisan kalimat di berbagai ranah, terutama ranah media sosial. Oleh karena itu, peneliti berfokus untuk mengkaji satu akun Instagram dengan nama @ young_lex18. Akun ini memiliki peran besar dan sangat berpengaruh dalam perkembangan Bahasa Indonesia dibandingkan akun Instagram yang lain. Hal ini ditunjukkan dengan adanya pengikut dengan jumlah mencapai jutaan dengan ratusan komentar dari pengguna akun yang lain. Adanya pengikut dan jumlah yang banyak ini menunjukkan bahwa akun ini mendapat perhatian yang besar dari masyarakat sehingga sangat berperan sebagai influencer dibandingkan akun yang lain. 
Penelitian ini memiliki beberapa tujuan pnelitian. Pertama, untuk mengetahui jenis kesalahan bahasa Indonesia yang sering terjadi di media sosial Instagram khususnya pada akun @ young_lex18. Kedua mendeskripsikan dan menganalisis letak kesalahan pada setiap unggahan dalam akun @young_lex18. Terakhir, memperbaiki kesalahan bahasa dalam unggahan akun @young_lex18 sehingga dapat terbentuk kalimat yang sesuai kaidah PUEBI.

Mengenai tema permasalahan yang diangkat, yaitu tentang penggunaan kaidah PUEBI dalam Instagram terdapat beberapa rumusan masalah yang akan dikaji. Yaitu, apakah jenis kesalahan yang sering terjadi pada akun Instagram @young_lex18? Bagaimanakah unggahan pada @young_lex18 dapat dikategorikan menyimpang dari PUEBI? Bagaimanakah perbaikan kalimat dalam akun Instagram @ young_lex18 agar sesuai kaidah PUEBI?. Berdasarkan latar belakang, tujuan, dan rumusan masalah yang diangkat, peneliti mengambil judul Instagram sebagai Media Peluntur Literasi dan Kosa Kata Bahasa Indonesia Instagram di Indonesia pada Era Revolusi Industri 4.0 di Kalangan Generasi Millenial

Berdasarkan riset kuantitatif Alvara Research Center menunjukkan bahwa Instagram menduduki peringkat kedua dari beberapa media sosial pada era milenial Indonesia. Populasi pengguna internet di Indonesia sebesar 83 juta jiiwa dengan populasi Instagram di Indonesia pada tahun 2015 mencapai 21 juta jiwa dan mengalami peningkatan pada tahun 2016 menjadi 22 juta jiwa, dengan jumlah Millenial muda lebih banyak dibandingkan Millenial dewas. Maka dari itu, generasi Millennial memegang peranan penting dalam perkembangan Instagram. (Ali dan Lilik, 2017)

Instagram.salah satu media sosial yang memengaruhi kelunturan kaidah bahasa Indonesia. Kelunturan bahasa ini ditunjukkan dengan munculnya kata-kata alai pada Instagram.. Melalui Instagram kata-kata baru tersebut menyebar dan terkenal di kalangan masyarakat. Fenomena tersebut akan merusak kaidah bahasa Indonesia yang benar yang sesuai dengan PUEBI sehingga bahasa Indonesia yang benar akan mengalami kelunturan bahkan kepunahan.

Beberapa alasan digunakannya media sosial Instagram sebagai media komunikasi adalah untuk melihat aktivitas yang diunggah, menjaga pertemanan, lebih kekinian, lebih tren dan hit di kalangan anak muda, dan sebagai media berwiraswata. (Ali dan Lilik, 2017)

Instagram akan menjadikan penggunanya lebih eksis dan terkenal di dunia maya. Efek positif dari penggunaan Instagram, pertama membangun stabilitas emosi penggunanya. Kedua, mebangun pola pikir yang kreatif, eksploratif, imajinatif, toleransi perbedaan, dan menghargai nilai-nilai artistik. Terakhir, mudah bergaul dengan teman-teman virtual sehingga dapat membangun relasi yang baik. (Tamimy, 2017

Instagram sangat berpengaruh terhadap perkembangan abreviasi bahasa Indonesia. Abreviasi tersebut lebih cenderung bersifat destruktif bahasa. Contoh penggunaan abreviasi atau kepanjangannya dalam media sosial Instagram yang diambil dari satu akun yang bernama @wanitasaleha. Terdapat unggahan yang berisi tentang kata yang dijadikan singkatan dan di plesetkan dari makna kata yang sebenarnya. Salah satunya yaitu kata TK merupakan bentuk singkatan dari tilawah konsisten. Sementara kata TK dalam bahasa Indonesia merupakan singkatan dari taman kanak-kanak. (Verlin, 2018)

Selain itu, terdapat banyak isu sosial yang terjadi di media sosial Instagram, salah satunya terjadi pada satu akun Instagram bernama @lambe_turah. akun ini merupakan akun gosip yang sangat terkenal di dunia maya. Akun ini menguak privasi orang tanpa memikirkan implikasi dan reaksi masyarakat menjadi masalah tersendiri. Instagram menjadi media yang sangat berpengaruh terhadap perubahan sosial dan mental publik. (Juditha, 2018)

Dalam dunia pendidikan, media sosial atau internet dimanfaatkan sebagai media pembelajaran dalam pendidikan. Menerapkan pembelajaran berbasis internet merupakan daya tarik tersendiri bagi siswa. Model pembelajaran ini memiliki karakteristik berfokus pada kemandirian siswa, guru sebagai fasilitator, dan pembelajaran dilakukan dalam kelas. (Wijaya, 2012) 
Pada beberapa mata pelajaran, Instagram dinilai sebagai media pembelajaran yang paling diminati siswa. Penggunaan media sosial Instagram berbasis foto sebagai tampilan dapat memudahkan pembelajaran karena dapat memuculan ide-ide baru, mendorong berpikir kreatif dan berimprovisasi dengan materi yang dipelajari, tidak terkesan monoton, dan dinilai lebih menarik, (Arumsari, 2018)

Sedangkan pada aspek sosial, Instagram dinilai berpengaruh terhadap Personal branding. Hal ini karena setiap unggahan merupakan cerminan karakter diri penggunanya yang dapat menimbulkan adanya penilaian positif atau negatif terhadap status sosial. (Tamimy, 2017)

\section{Kajian Pustaka}

Pada penelitian ini, menggunakan sumber data sekunder berupa buku dan jurnal untuk memperkuat keabsahan analisis data primer. Buku dan jurnal yang digunakan adalah termasuk dalam kategori terbitan terbaru, dengan catatan lima tahun 6 tahun terakhir agar dapat diperoleh data yang baik kualitasnya.

Bahasa Indonesia yang baik dan benar harus diterapkan dalam segala aspek. Bahasa yang baik adalah adalah bahasa yang menekankan aspek komunikatif. Hal ini berarti kita harus memerhatikan sasaran kepada siapa kita berbicara.Sedangkan bahasa yang benar adalah bahasa yang sesuai dengan peraturan kaidah bahasa, yaitu PUEBI. (Hidayah, 2016)

Setiap tulisan harus ditulis sesuai dengan PUEBI dan selalu merujuk pada KBBI. Hal ini bertujuan agar mutu tulisan semakin baik dari hari ke hari. Minat membaca perlu dikembangkan pada diri masing-masing karena bacaan yang kita baca akan berpengaruh pada kualitas tulisan kita. Maka dari itu perlu bagi kita membaca bacaan yang berkualitas. (Listiyani, 2018)

Bahasa baku disebut juga bahasa standar. Bahasa standar selalu berkaitan dengan ragam bahasa yang diterima untuk dipakai dalam situasi resmi seperti perundang-undangan, surat menyurat, dan memilki fungsi sebagai pemersatu di antara keanekaragaman bahasa di Indonesia. ( Kamdhi, 2006)

Bahasa baku meupakan bentuk bahasa yang telah dikodifikasi atau ditetapkan, diterima dan diifungsikan sebagai model oleh masyarakat luas, sebagai patokan umum untuk seluruh penutur bahasa itu (Fahrurrozi dan Andri, 2016)

Terdapat empat dasar penulisan bahasa Indonesia, yaitu pemakaian huruf, penulisan kata, pemakaian tanda baca, dan penulisan unsur serapan. Salah satu yang sering kita pakai adalah pemakain huruf kapital. Huruf kapital digunakan ketika terdapat di awal kalimat, huruf pertama judul, nama orang, nama gelar, nama Tuhan,nama bangsa, nama hari,nama geografi, peristiwa sejarah, dan lain-lain. PUEBI (2016)

\section{Metode Penelitian}

Metode penelitian yang diterapkan adalah metode deskriptif kualitatif. Metode penelitian ini dilakukan dengan membandingkan dan mengamati, dan menganalisis unggahan satu dengan unggahan lainnya dari segi kesesuaian terhadap kaidah bahasa Indonesia atau PUEBI. Hal tersebut untuk memberikan gambaran sedetail mungkin sesuai dengan kenyataan pada media sosial Instagram. Sumber data yang digunakan berupa data primer dalam penelitian ini diperoleh dari media sosial Instagram pada akun@young_lex18 berupa foto yang bertuliskan berbagai tulisan yang menyimpang dari PUEBI. Selanjutnya, data sekunder diperoleh dari penelitian yang berasal dari penelitian yang relevan dengan objek kajian, seperti buku-buku dan jurnal. Populasi penelitian ini, yaitu semua bentuk unggahan beserta keterangan berbentuk tulisan dalam akun Instagram @young_lex18 yang berupa foto dengan jumlah 2320 unggahan denagan sampel yang digunakan sejumlah 50 unggahan. Metode Pengumpulan data dilakukan dengan melakukan penelusuran unggahan-unggahan pada akun Instagram @young_lex18. 
Kemudian melakukan tangkap layar pada unggahan tersebut. Setelah itu, unggahan tersebut dianalisis secara detail tentang letak penyimpangan PUEBI dengan adanya pencatatan dan pengklasifikasian terhadap jenis penyimpangan yang direalisasikan dalam bentuk tabel.

\section{Pembahasan}

Tabel 4.1 jenis kesalahan yang terjadi beserta frekuensinya pada aku Instagram @young_lex18

\begin{tabular}{|c|c|c|c|c|c|}
\hline No & Jenis kesalahan & Frekuensi & No & Jenis kesalahan & Frekuensi \\
\hline 1 & Tanda baca & 29 & \multirow[t]{6}{*}{7} & \multirow{6}{*}{$\begin{array}{l}\text { Penulisan kata (kata dasar, } \\
\text { imbuhan, perulangan, } \\
\text { gabungan, kata depan, } \\
\text { singkatan dan akronim, angka } \\
\text { dan bilangan, kata ganti) }\end{array}$} & \multirow[t]{6}{*}{16} \\
\hline 2 & Huruf kapital & 44 & & & \\
\hline 3 & Mencampuradukkan bahasa & 21 & & & \\
\hline 4 & Tidak sesuai KBBI & 21 & & & \\
\hline 5 & Galat & 2 & & & \\
\hline 6 & Konjungsi & 4 & & & \\
\hline
\end{tabular}

Penelitian ini berfokus untuk mengkaji satu akun Instagram dengan nama @young_lex18. Akun ini merupakan akun yang memiliki peran besar dan sangat berpengaruh dalam perkembangan Bahasa Indonesia dibandingkan akun Instagram yang lain. Hal ini ditunjukkan dengan adanya pengikut dengan jumlah mencapai jutaan dengan ratusan komentar dari pengguna akun yang lain. Adanya pengikut dan jumlah yang banyak ini menunjukkan bahwa akun ini mendapat perhatian yang besar dari masyarakat sehingga sangat berperan sebagai influencer dibandingkan akun yang lain.

Pembahasan ini berfokus pada titik kesalahan penulisan bahasa Indonesia yang tidak sesuai dengan kaidah PUEBI. Data diperoleh dengan menganalisis 50 sampel unggahan dari 2320 unggahan pada akun @young_lex18. Diperoleh beberapa data kesalahan dengan frekuensi yang bervariasi Frekuensi tertinggi terdapat pada jenis kesalahan penggunaan huruf kapital dengan jumlah frekuensi sebanyak 44 dari 50 sampel unggahan dan frekuensi terendah terdapat pada kesalahan kata berupa galat yang hanya muncul sebanyak dua kali dari keseluruhan sampel yang dianalisis. Pada pembahasan ini, akan dibahas dan dianalisis secara mendalam pada 3 unggahan akun @young_lex18. Hal ini karena peneliti ingin mengkaji, mendeskripsikan, dan menganalisis secara mendalam dan bersifat keseluruhan pada beberapa kategori tertentu, yaitu pada akun dengan kategori frekuensi paling tinggi, paling rendah, dan paling unik. Hal ini ditunjukkan oleh unggahan berikut ini,

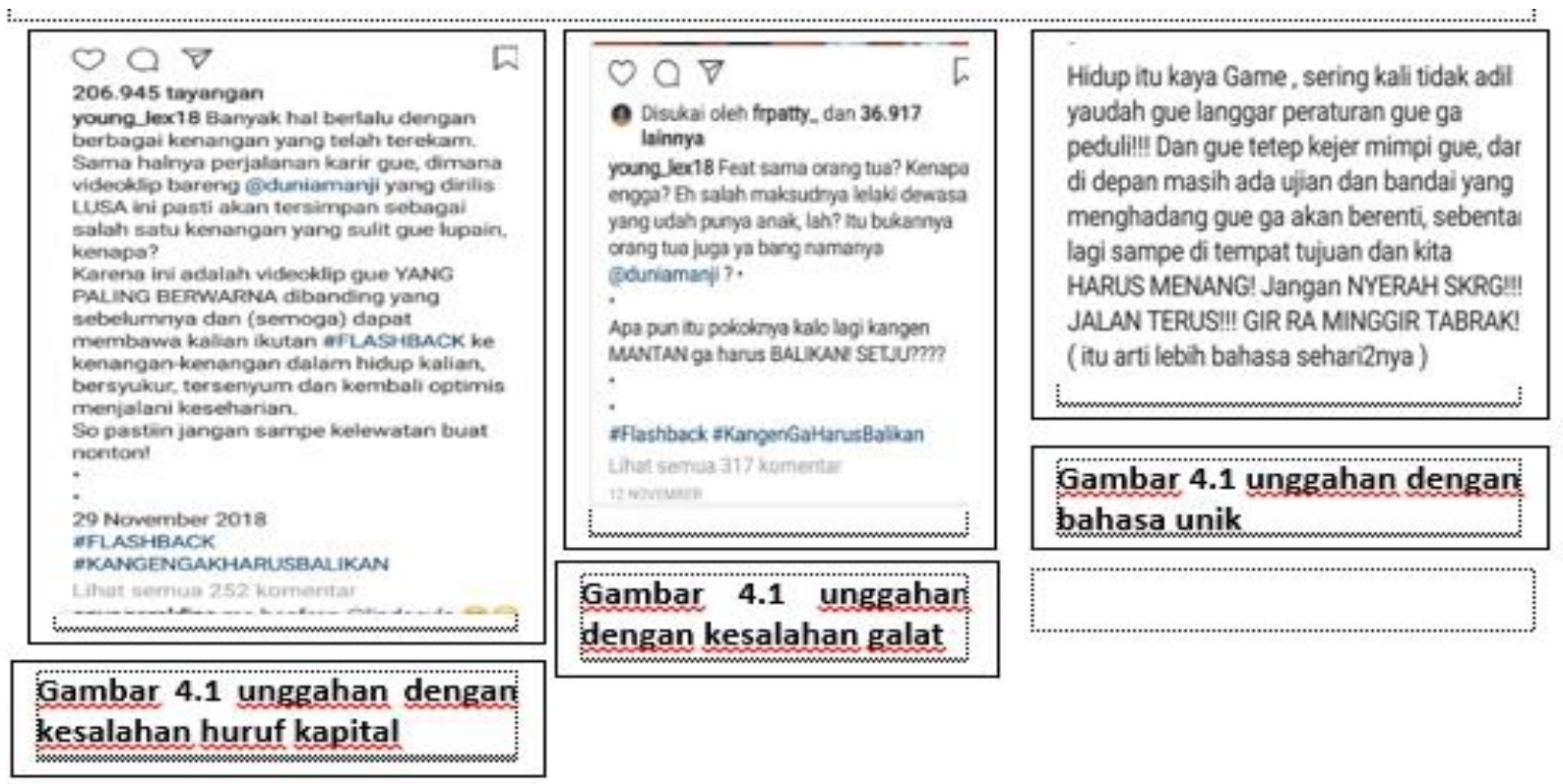


Berdasarkan data unggahan yang ditunjukkan pada gambar 4.1, tercatat bahwa kesalahan yang sering muncul pada akun Instagram @young_lex18 adalah kesalahan penggunaan huruf kapital. Kesalahan ini ditunjukkan pada kalimat "YANG PALING BERWARNA", "FLASHBACK", dan "KANGENGAKHARUSBALIKAN". Berdasarkan PUEBI, penulisan ini dikatakan salah. Hal ini dikarenakan kalimat tersebut terletak di tengah kalimat, bukan termasuk judul, dan bukan nama seseorang, bukan sapaan, bukan nama gelar, bukan hari besar, bukan nama geografi dan juga bukan jenis kalimat yang harus ditulis menggunakan huruf kapital seperti yang telah disebutkan pada bab tinjauan pustaka di kajian sebelumnya. Tulisan tersebut akan menjadi benar apabila ditulis menggunakan huruf kecil, penulisan "YANG PALING BERWARNA" diubah menjadi "yang paling berwarna". Kemudian "FLASHBACK" diganti huruf kecil dan dimiringkan menjadi "flashback". Hal ini dikarenakan "flashback" merupakan bahasa asing maka penulisannya harus dimiringkan selain diganti menjadi huruf kecil. Terakhir, penulisan "KANGENGAKHARUSBALIKAN" harus diubah menjadi " kangen tidak harus kembali ". Terdapat beberapa bentuk pengubahan yaitu diubah menjadi huruf kecil, ditambah spasi antar kata, dan beberapa kata diubah sesuai KBBI. Perubahan kata sesuai KBBI meliputi perubahan kata "GAK" menjadi "tidak" dan kata "BALIKAN" menjadi "kembali".

Selanjutnya, pada gambar 4.2 terdapat kesalahan penulisan kata yang sering kita sebut galat. Kesalahan galat ini terdapat pada penulisan kata "SETJU". Terdapat kesalahan pengetikan pada kata "SETJU". Terdapat kesalahan berupa hilangnya satu huruf penyusun kata tersebut, yaitu huruf "u". maka dari itu, seharusnya kata "SETJU" diganti menjadi "SETUJU" agar tidak terjadi galat dalam penulisan. Selain itu, apabila dianalisis lebih lanjut terdapat kesalahan penggunaan huruf kapital. Kata "SETUJU" harus dibenarkan menjadi "setuju" agar sesuai dengan kaidah PUEBI.

Terakhir, pada gambar 4.3 terdapat sisi unik dari unggahan ini. Sisi unik tersebut berupa adanya kalimat sejenis peribahasa dan kalimat motivasi penyemangat yang merupakan penyampuran antara bahasa Jawa dengan bahasa Indonesia. Terdapat kata "RA" yang menunjukkan bahasa Jawa yang memiliki arti "tidak" dalam bahasa Indonesia. Apabila dlihat dari sudut pandang kaidah bahasa Indonesia atau PUEBI, terdapat banyak kesalahan dalam unggahan ini. Pertama, adanya kesalahan berupa menyampuradukkan bahasa Indonesia dengan bahasa asing seperti kata "game" yang merupakan bahasa Inggris dan kata "ra" yang merupakan bahasa Jawa. Kedua, terdapat kesalahan pemenggalan kata seperti pada kata "yaudah" seharusnya diubah menjadi " ya sudah". Ketiga, adanya kesalahan penggunaan tanda baca seperti tanda seru(!) seharusnya ditulis sekali saja karena selain tidak sesuai ejaan juga termasuk bersifat mubazir. Keempat, adanya galat pada penulisan "kejer", kata ini seharusnya dibenarkan menjadi "kejar", dengan mengganti huruf e menjadi huruf a. Kelima, ditemukannya kata yang tidak sesuai dengan KBBI, yaitu kata "berenti". Menurut KBBI, kata tersebut seharusnya diganti menjadi "berhenti". Keenam, terdapat kata yang penulisannya disingkat, yaitu kata "SKRG" kata ini seharusnya diganti menjadi tulisan aslinya dan ditulis menggunakan huruf kecil, yaitu menjadi "sekarang" dan kata "gir" harus diganti "minggir". Ketujuh, kata "langgar" dan kata "nyerah" dinilai tidak sesuai dengan kaidah ejaan bahasa Indonesia atau PUEBI karena tidak menggunakan awalan "me", padahal kata ini merupakan kata kerja aktif. Oleh karena itu, harus diubah menjadi "melanggar" dan "menyerah". Kedelapan yang terakhir, kalimat "HARUS MENANG! Jangan NYERAH SKRG!!! JALAN TERUS!!! GIR RA MINGGIR TABRAK!!!" harus dibenahi menjadi "harus menang! Jangan menyerah sekarang! Jalan terus! Minggir tidak tidak minggir ditabrak!”

\section{Kesimpulan}

Berdasarkaan pembahasan analisis data [enelitian, dapat disimpulkan bahwa,

5.1 Jenis kesalahan yang sering muncul pada akun Instagram @young_lex18 adalah kesalahan penulisan huruf kapital dengan frekensi paling tinggi dan kesalahan yang paling jarang muncul adalah kesalahan galat dengan frekuensi terendah. 
5.2 Letak kesalahan yang terjadi adalah pada unggahan dengan menggunakan huruf kapital pada keseluruhan kata. Semua kata yang ditulis didominasi dengan huruf kapital

5.3 Kesalahan penulisan dapat diperbaiki dengan menimbang kaidah peraturan penulisan pada PUEBI dan meninjau penggunaan kata melalui KBBI.

\section{Daftar Pustaka}

Ali, Hasanuddin dan Lilik Purwandi. (2017). Millennial Nusantara. Jakarta : Gramedia Pustaka Utama. Tamimy, Muhammad Fidhol. (2017). Sharing-Mu Personal Branding-Mu. Jakarta : Visi Media.

Verlin, S. (2018). Abreviasi Dalam Media Sosial Instagram. Jurnal Ilmu Budaya, 6(2), 277-286.

Juditha, C. (2018). Hegemoni Media Sosial: Akun Gosip Instagram@ Lambe_Turah Sosial Media

Hegemony: Gosip Instagram Account@ Lambe_Turah. Jurnal Penelitian Komunikasi dan Opini Publik Vol, 22(1), 16-30.

Wijaya, M. (2012). Pengembangan Model Pembelajaran E-Learning Berbasis Web dengan Prinsip EPedagogy dalam Meningkatkan Hasil Belajar. Jurnal Pendidikan Penabur, 11(19), 20-27.

Arumsari, D. (2018). Penggunaan Media Sosial Instagram Berbasis Foto sebagai Output Dalam Mata Kuliah Essei Sakubun.

Hidayah, Nurul, 2016, Pembelajaran Bahasa Indonesia dii Perguruan Tinggi, Yogyakarta

Garudhawacana.

Listiyani, Alif Kiki. Dkk, 2018, One Day One Post, Sidoarjo : Embrio.

Kamdhi, J.S. (2006). Terampil Berwicara Smu 2. Jakarta : Grasindo.

Fahrurrozi Dan Andri Wicaksono. (2016). Sekilas Tentang Bahasa Indonesia: Catatan

Mengenai Kebijakan Bahasa, Kaidah Ejaan, Pembelajaran Satra, Penerjemahan, dan Bipa, Yogyakarta: Garudhawaca.

Tim Pengembang Pedoman Bahasa Indonesia. (2016). Pedoman Umum Ejaan Bahasa Indonesia Edisi Keempat. Jakarta : Kemendikbud. 